\title{
Who donates? Cross-country and periodical variation in blood donor demographics in Europe between 1994 and 2014
}

\author{
Nathan Wittock (D, Lesley Hustinx, Piet Bracke, and Veerle Buffel
}

\begin{abstract}
BACKGROUND: Ageing European populations put pressure on national blood supplies, increasing the need for blood and donor base rejuvenation. Therefore, we investigate how European countries' blood donor populations differ and how they have evolved over the last 2 decades. Previous comparative research, based on 1994 Eurobarometer data, indicate that the typical donor is an educated, middle-aged, white, married male. Other sociodemographic and socioeconomic correlates, such as employment status and type of community, are less clear.
\end{abstract}

STUDY DESIGN AND METHODS: Multilevel analyses are performed on repeated cross-level data from the Eurobarometer (waves 1994, 2002, 2009, and 2014) to compare information on "ever having donated" across sociodemographic categories, countries, and periods.

RESULTS: There are consistent but moderate country and period differences. The donor population rose to become largest in most countries by 2009 , and stabilized thereafter. Over the studied period, donors were more likely to be higher educated, married men. Nevertheless, changes across time in donor profiles within countries did occur. Women were less likely to donate blood, especially in Southern and Eastern Europe, but this gender gap has declined. Furthermore, educational attainment seems more relevant for women, although, more recently, to a lesser extent.

CONCLUSION: Although there is a promising trend in which women, young people, and students are increasingly likely to donate, more attention is needed to reach the unemployed and the low to medium educated. Because the unemployed may lack structural opportunities to donate, and the low to medium educated may lack relevant knowledge on blood donation necessity, we recommend providing practical opportunities and information on the necessity of blood donation.
$\mathrm{T}$ he therapeutic use of donor-sourced blood remains an important part of European medical practice, ${ }^{1}$ and demographic trends have been identified as putting pressure on its (future) procurement. $^{2,3}$ Although it has been argued that models assuming continuous demand according to age and gender typically overestimate future demand, ${ }^{3}$ others suggest that the need for blood is increasing due to progress in hematology, oncology, and rising numbers of major surgical procedures. ${ }^{4}$ Because population ageing applies to all European member states, multilateral exchange agreements in case of need may lose their current buffering potential. $^{1,4}$ Therefore, donor recruitment is and will be a major challenge for blood establishments to succeed in their mission to provide safe and sufficient amounts of blood for a designated region. ${ }^{5}$

Alongside the demographic shift, two important institutional changes have occurred since previous crossnational reports on blood donation in Europe, which used data from 1994. ${ }^{6}$ First, the development of the Blood Directives, which had the primary aim of harmonizing national policies concerning general, technical, quality, and traceability standards, ${ }^{5}$ could result in donor populations becoming increasingly comparable over time. However, trends could equally reflect an altered blood donor profile because of the second institutional change, European Union (EU) enlargement, since Central and Eastern European countries-which entered the EU after the 1994

From the Department of Sociology, Ghent University, Ghent, Belgium.

Address reprint requests to: Nathan Wittock, Department of Sociology, Ghent University, Korte Meer 5, BE-9000 Ghent, Belgium; nathan.wittock@ugent.be

This research was supported in part by research grant G0D1415N from the Research Foundation-Flanders (FWOVlaanderen).

Received for publication April 19, 2017; revision received June 9, 2017; and accepted June 9, 2017.

doi:10.1111/trf.14272

(C) $2017 \mathrm{AABB}$

TRANSFUSION 2017;00;00-00 
survey-are characterized by more rapid demographic and sociopolitical changes from the early 1990s onward., ${ }^{4,7}$ To assess whether these demographic and institutional changes have (differentially) impacted EU member states' blood donor populations, we asked, "How do European countries' blood donor populations differ, and how have they evolved in the last 2 decades?"

Most recent research on donor characteristics and donation behavior has focused on either case studies and qualitative research ${ }^{8-15}$ or experimental designs. ${ }^{16-19}$ Large-scale quantitative research is scarce. When performed, it is mostly based on single-country, single-period samples. ${ }^{4,18,20-26}$ In these studies, the typical donor is male, well educated, healthy, white, married with children, and has a rare blood type. ${ }^{4,6,26}$ In addition, within the overall population of donors, different donor profiles have been distinguished on the basis of gender, age, socioeconomic status, and ethnicity, ${ }^{9,11,16,20,27-29}$ with the frequency of blood donation being significantly higher for male, older, white, and educated individuals. ${ }^{26}$

Previous cross-country research on the basis of the 1994 Eurobarometer found differences in donation rates between the EU12. ${ }^{6}$ However, this research did not examine evolutions over time, and the structural changes of the EU and its population urge an updated vision. To our knowledge, the one cross-national study that does take into account cross-temporal developments ${ }^{30}$ only compares the German and Swiss populations. That research identified similar sociodemographic differences, with a greater likelihood of donating blood among men and the highly educated. These educational and gender differences were more pronounced in Switzerland, whereas the gender gap decreased over time in Germany.

Using information from the Eurobarometer, which is a representative data set of the general population in all EU countries, we can provide further evidence on crosscountry and cross-temporal differences in blood donation patterns. To the best of our knowledge, the present study is the first to examine blood donation prevalence across a wide range of European countries during a period of 2 decades using a multilevel framework.

\section{MATERIALS AND METHODS}

\section{Sample}

The data were provided by the Eurobarometer surveys, rounds 41.0 (1994), 58.2 (2002), 72.3 (2009), and 82.2 (2014), which include information on the general population ages 15 years and older in 12, 15, 27, and 28 EU member states, respectively. To our knowledge, the Eurobarometer is the only repeated cross-national survey that combines nationally representative samples, information on blood donation, and comparable measurements of sociodemographic and socioeconomic characteristics. The basic sample design used in all countries comprises a multi-stage, random (probability) sample of individuals within households within an area. Interviews were conducted face-to-face in the national language.

We used a subsample limited to respondents of potential donor age (range, 18-65 years), which resulted in 75,298 respondents. We chose 65 years as the upper age limit, because, although some countries allow blood donation by individuals older than 65 years under certain circumstances, those aged 65 years and older are defined as the "dependent" category in the demographic old-agedependency ratio. ${ }^{31}$ Therefore, we align with other research taking into account ageing populations in Europe. There were 12,274 missing values (16.5\%), and those respondents were omitted from the sample. Consequently, the final sample contains information for 62,237 respondents. Descriptive statistics and the sample size per country and period are provided in Appendix S1, available as supporting information in the online version of this paper.

\section{Measurements}

As in previous cross-country and cross-period research on blood donation, ${ }^{30}$ our outcome variable, blood donation lifetime prevalence, is based on the question, "Have you ever given blood?" Answers were scored as 1 for donors and 0 for nondonors.

In accordance with other research, we also included information on educational attainment, age, and marital status. ${ }^{4,6,26}$ For education levels, respondents were asked about the age at which they finished full-time education. The EU (Eurobarometer) provides a standard classification in three categories: ages up to 15 years, 16 to 19 years, and 20 years or older. This corresponds approximately to primary (low), secondary (middle), and tertiary (high) education. Although outliers are possible, this standard measure enhances the comparability of education systems between countries. ${ }^{32,33}$ In addition, to reduce the influence of outliers, respondents who reported a number of years that was three standard deviations from the country mean were removed from our sample. ${ }^{34}$ The age of the respondent at the time of the survey is categorized into four age groups: 18 to 29 years, 30 to 44 years, 45 to 54 years, and 55 to 65 years. Marital status is also a four-category variable: (re)married or legal cohabitation, single, divorced or separated, and widowed.

We include two other variables that have been less researched to date. ${ }^{35,36}$ First, research on donor motivators and deterrents has shown that adequate donation site accessibility is a strong motivator, and inconvenience is a strong deterrent. ${ }^{8,37}$ This makes information on the type of community of the donor population an important factor that influences decision making based on the collection site location. The degree of urbanization has the following categories: rural area or village (rural), small or medium-sized town (small urban), and large town (urban). 


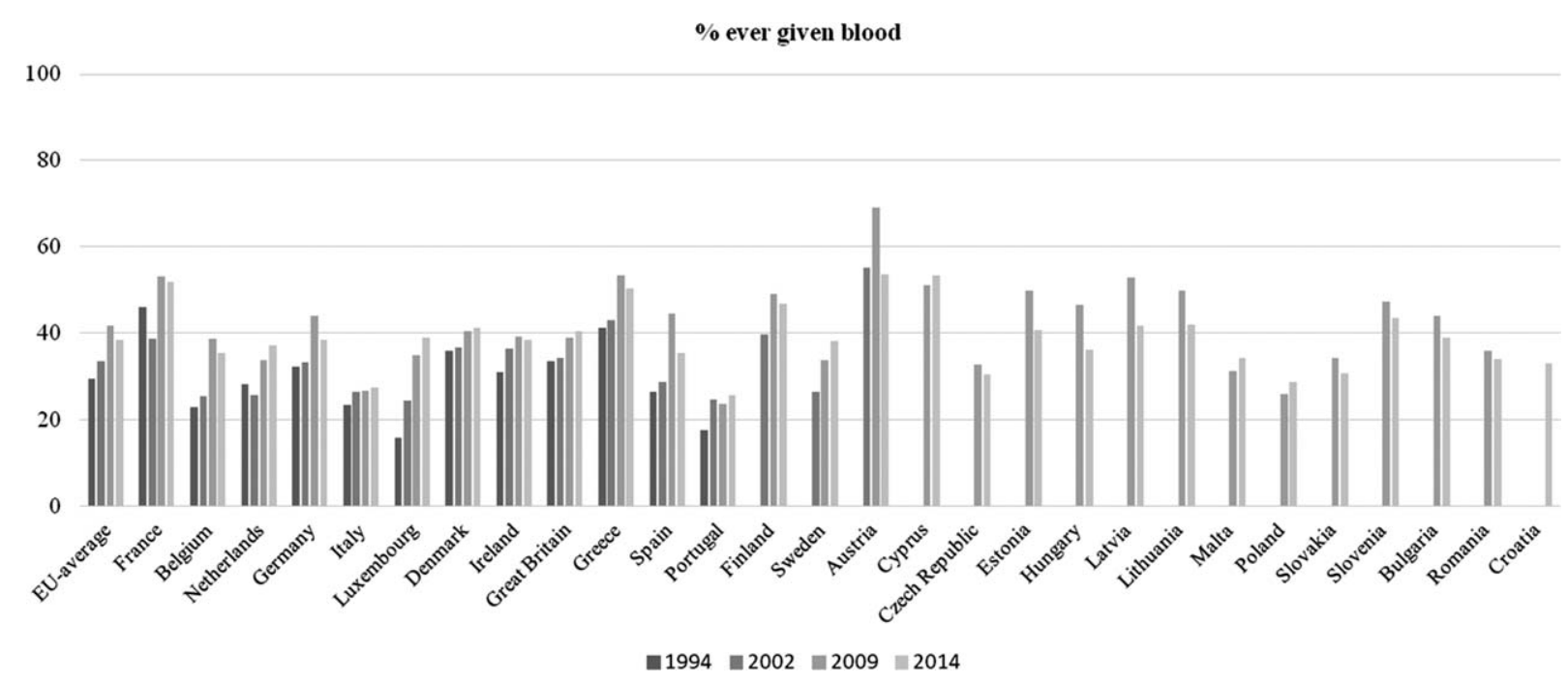

Fig. 1. The percentage of people who have ever given blood per country and period; countries are listed from left to right according to European Union membership attainment.

Second, evidence suggests a connection between employment status and the likelihood of donating blood. ${ }^{38,39}$ Because donor selection has become more stringent and time consuming, however, it is possible that the employed self-defer from blood donation. ${ }^{40}$ To further explore this connection, we include employment status in five categories: employed, homemaker, student, retired or inactive due to disability or sickness, and unemployed.

Given the aim for policy harmonization through the Blood Directives, we would expect donor populations to become increasingly more comparable over time. However, because overall EU demographics have changed through the expansion rounds, ${ }^{7}$ the trend could equally reflect a changed blood donor profile. Therefore, the categorical variable period and a country-level variable on membership status attainment (four categories) are included in the models. The latter allow consideration of which countries were included in the Eurobarometer survey from Round 1 (1994; EU12), Round 2 (2002; EU15), Round 3 (2009; EU27), and Round 4 (2014; EU28).

\section{Statistics}

Our analyses comprise two parts. First, we discuss some descriptive results. Country and period differences in prevalence rates of blood donation are presented in Fig. 1 and Appendix S1. Bivariate analyses give us an overview for each period of the differences between the blood donor population and those who have never given blood (pairwise Pearson chi-square tests). The results are shown in Table 1.

Second, a three-level framework allows us to compare the influence of demographics on ever having donated, both between countries and over time. Logistic multilevel analysis enables us to take into account the clustering of data in periods as well as countries. ${ }^{39}$ We examine the clustering of different waves within countries, because four periods are not enough to use period as a separate level. ${ }^{41}$ Consequently, 62,237 individuals (first level) are nested in 82 country-periods (second level), which are nested in 28 countries (third level). The results of the logistic multilevel analysis are provided in Table 2 .

To explore whether there are general periodical trends in blood donation, the first model includes the period variable only. In the second model, we add the sociodemographic and socioeconomic variables in a stepwise fashion to assess the extent to which the period differences could be ascribed to a different composition of the population. Furthermore, "EU inclusion of country from Round 1, 2, 3, or 4" is added to test whether the period effects are not just a reflection of the growing number of countries included in the analyses. In the third model, to further investigate whether donor profile characteristics changed over the periods, cross-level interactions are estimated with the period variable in the subsequent models. Nonsignificant interaction effects are excluded from the analysis to enhance interpretability and to provide a more parsimonious model. Given the differential influence of education for men and women reported in previous work, ${ }^{30}$ we also performed a threeway interaction with period, gender, and education to further expand on these findings with more European countries in the comparison and by introducing a more elaborate cross-temporal comparison. To make the odds ratios more comparable across the nested models, ystandardization was performed, as is recommended practice. ${ }^{42}$ Results from the logistic multilevel analyses for the different models are shown in Table 2. 


\begin{tabular}{|c|c|c|c|c|c|c|c|c|}
\hline \multirow[b]{3}{*}{ Variable } & \multicolumn{8}{|c|}{ Ever given blood, \% } \\
\hline & \multicolumn{2}{|c|}{1994} & \multicolumn{2}{|c|}{2002} & \multicolumn{2}{|c|}{2009} & \multicolumn{2}{|c|}{2014} \\
\hline & No & Yes & No & Yes & No & Yes & No & Yes \\
\hline$\overline{\text { Total }}$ & & 30.3 & & 33.4 & & 41.7 & & 38.4 \\
\hline Male & 44.3 & 60.5 & 42.0 & $55.3^{*}$ & 38.1 & $52.8^{*}$ & 40.2 & $50.4^{*}$ \\
\hline Female & 55.7 & 39.5 & 58.0 & 44.7 & 61.9 & 47.2 & 59.8 & 49.6 \\
\hline \multicolumn{9}{|l|}{ Age category, years } \\
\hline $18-29$ & 31.2 & $21.1^{\star}$ & 28.7 & $17.7^{\star}$ & 23.7 & $14.9^{*}$ & 20.5 & $14.2^{*}$ \\
\hline $30-44$ & 32.1 & $39.1^{\star}$ & 34.4 & $35.5^{\star}$ & 33.0 & $32.9^{*}$ & 32.9 & $30.9^{*}$ \\
\hline $45-54$ & 17.9 & $23.0^{*}$ & 17.8 & $24.7^{\star}$ & 20.5 & $24.8^{*}$ & 21.0 & $24.9^{*}$ \\
\hline $55-65$ & 18.8 & $16.7^{\star}$ & 19.1 & $22.1^{*}$ & 22.8 & $27.5^{\star}$ & 25.6 & $30.1^{*}$ \\
\hline \multicolumn{9}{|l|}{ Marital status } \\
\hline (Re)married/cohabiting & 65.0 & $71.4^{\star}$ & 62.8 & $67.2^{*}$ & $66.7^{\star}$ & $70.8^{\star}$ & 67.8 & $71.2^{*}$ \\
\hline Single & 26.3 & $19.5^{\star}$ & 26.2 & $19.7^{\star}$ & $21.6^{\star}$ & $17.0^{\star}$ & 20.6 & $15.5^{*}$ \\
\hline Divorced or separated & 5.2 & 5.8 & 8.0 & $10.1^{*}$ & 7.8 & $8.8 \dagger$ & 8.3 & 9.9 \\
\hline Widowed & 3.5 & 3.3 & 3.0 & 3.0 & 3.8 & 3.3 & 3.4 & 3.4 \\
\hline \multicolumn{9}{|l|}{ Type of community } \\
\hline Rural or village & 38.0 & 35.8 & 36.5 & 33.5 & 35.7 & 36.3 & 30.4 & 29.7 \\
\hline Small urban & 33.7 & 32.3 & 31.0 & 30.1 & 35.7 & 32.7 & 42.0 & 41.4 \\
\hline Urban & 28.3 & $31.9^{*}$ & 32.6 & 34.6 & 28.6 & $31.0^{*}$ & 27.6 & $28.9 \dagger$ \\
\hline \multicolumn{9}{|l|}{ Education } \\
\hline Low & 29.4 & $22.5^{\star}$ & 21.5 & $18.1^{*}$ & 16.0 & $12.0^{\star}$ & 11.3 & 9.1 \\
\hline Middle & 40.8 & $43.3^{*}$ & 42.9 & $44.4^{*}$ & 48.9 & $49.0^{*}$ & 48.2 & $* 44.5$ \\
\hline High & 29.7 & $34.2^{*}$ & 35.6 & $37.5^{\star}$ & 35.1 & $39.0^{*}$ & 40.5 & $46.4^{*}$ \\
\hline \multicolumn{9}{|l|}{ Employment status } \\
\hline Homemaker & 17.5 & $10.2^{*}$ & 13.8 & $8.3^{*}$ & 11.3 & $6.6^{*}$ & 7.6 & $4.7^{*}$ \\
\hline Student & 9.8 & $5.5^{*}$ & 9.4 & $4.8^{*}$ & 6.9 & $4.2^{*}$ & 7.3 & $4.8^{*}$ \\
\hline Unemployed & 8.3 & $6.5^{*}$ & 6.6 & 5.6 & 8.9 & $7.6^{*}$ & 11.5 & $7.8^{*}$ \\
\hline Retired or inactive due to disability & 10.3 & 9.3 & 10.3 & $12.3^{*}$ & 13.2 & $15.3^{*}$ & 13.1 & $15.0^{*}$ \\
\hline Employed & 54.1 & $68.5^{\star}$ & 59.9 & $69.0^{*}$ & 59.7 & $66.3^{*}$ & 60.6 & $67.6^{*}$ \\
\hline
\end{tabular}

Next, because lifetime prevalence accumulates with age and is logically higher for older people-who have had more time and opportunities to have ever donated blood throughout their life-we re-estimate our models on the youngest age category to obtain a better indication of whether there is a rejuvenation of the blood donor group (Appendix S2). In addition, sensitivity analyses are performed. The models are re-estimated with birth cohort included (1929-1945, 1946-1962, 1963-1979, and 19801996) instead of age category (Appendix S3). Finally, country-specific logistic regression analyses are carried out with period as a fixed effect to obtain a more detailed picture of the differences between countries (Appendix S4.1-S4.5).

\section{RESULTS}

\section{Country-specific prevalence rates and bivariate analyses per period}

The average proportion of people who have ever given blood over the four periods and in all EU countries is $37.0 \%$. The blood donation rate increased significantly from 1994 to 2009, with a small decrease later in 2014. In most countries, a similar increasing pattern is observed, whereas the decrease from 2009 to 2014 is significant in
Germany, Spain, Austria, Estonia, Hungary, Latvia, Lithuania, and Bulgaria (Model 1, Appendix S4). Figure 1 shows that Italy, Portugal, and Poland have relatively low prevalence rates. France, Greece, Austria, Cyprus, and Latvia, by contrast, have a relatively high prevalence rate in each period. Finally, no apparent clustering of countries (e.g., an East-West divide or EU-enlargement rounds) in terms of donor prevalence can be observed.

The results of the bivariate analyses (Table 1) confirm that the typical donor is male, married, between 30 and 44 years old, and employed. However, there are some notable period differences. Whereas, for the period from 1994 to 2009, the typical donor had obtained a secondary education, by 2014, this changed to a tertiary education. In addition, by 2014 , the gender gap had nearly disappeared. Regarding the type of community, the figures are not straightforward. In each period, the donor group is significantly more likely to live in large towns. In 1994, the typical donor was significantly less likely to live in a rural area.

\section{Multilevel analyses}

From the variance decomposition of the null model (not shown), we note that there is a significant but small variance in blood donor status at the higher levels: (variance partition coefficient country + period $=\left[\sigma^{2}\right.$ country + 


\begin{tabular}{|c|c|c|c|c|c|c|}
\hline & \multicolumn{6}{|c|}{ Odds ratio } \\
\hline & Model 1 & Model 2 & Model 3 & Model 4 & Model 5 & Model 6† \\
\hline Constant & $0.826 \ddagger$ & 1.111 & $1.135 \S$ & 1.110 & 1.099 & 1.080 \\
\hline \multicolumn{7}{|l|}{ Period (Ref. 2009) } \\
\hline 1994 & $0.770 \ddagger$ & $0.813 \ddagger$ & $0.808 \ddagger$ & $0.880 \ddagger$ & $0.854 \ddagger$ & $0.804 \ddagger$ \\
\hline 2002 & $0.814 \ddagger$ & $0.837 \ddagger$ & $0.820 \ddagger$ & $0.832 \ddagger$ & $0.851 \ddagger$ & $0.805 \ddagger$ \\
\hline 2014 & $0.939 \ddagger$ & $0.910 \ddagger$ & $0.865 \ddagger$ & $0.883 \ddagger$ & $0.914 \ddagger$ & $0.875 \ddagger$ \\
\hline \multicolumn{7}{|l|}{$\begin{array}{l}\text { EU inclusion } \\
\quad \text { (Ref. from 1994) }\end{array}$} \\
\hline From 2002 & & 1.169 & 1.170 & 1.168 & 1.169 & 1.169 \\
\hline From 2009 & & 1.028 & 1.028 & 1.027 & 1.027 & 1.030 \\
\hline From 2014 & & 0.955 & 0.954 & 0.954 & 0.958 & 0.960 \\
\hline \multicolumn{7}{|l|}{$\begin{array}{l}\text { Employment status } \\
\text { (Ref. employed) }\end{array}$} \\
\hline Homemaker & & $0.804 \ddagger$ & $0.808 \ddagger$ & $0.803 \ddagger$ & $0.817 \ddagger$ & $0.828 \ddagger$ \\
\hline Student & & $0.813 \ddagger$ & $0.813 \ddagger$ & $0.809 \ddagger$ & $0.826 \ddagger$ & $0.821 \ddagger$ \\
\hline Unemployed & & $0.861 \ddagger$ & $0.861 \ddagger$ & $0.861 \ddagger$ & $0.910 \|$ & $0.860 \ddagger$ \\
\hline $\begin{array}{l}\text { Retired or inactive } \\
\text { due to disability }\end{array}$ & & $0.944 \ddagger$ & $0.944 \ddagger$ & $0.944 \ddagger$ & 0.982 & $0.942 \ddagger$ \\
\hline Sex (Ref. male) & & $0.750 \ddagger$ & $0.721 \ddagger$ & $0.750 \ddagger$ & $0.751 \ddagger$ & $0.792 \ddagger$ \\
\hline \multicolumn{7}{|l|}{$\begin{array}{l}\text { Age category, years } \\
\text { (Ref. } 30-44 \text { years) }\end{array}$} \\
\hline $18-29$ & & $0.802 \ddagger$ & $0.802 \ddagger$ & $0.778 \ddagger$ & $0.800 \ddagger$ & $0.801 \ddagger$ \\
\hline $45-54$ & & $1.146 \ddagger$ & $1.145 \ddagger$ & $1.134 \ddagger$ & $1.148 \ddagger$ & $1.149 \ddagger$ \\
\hline $55-65$ & & $1.145 \ddagger$ & $1.145 \ddagger$ & $1.189 \ddagger$ & $1.147 \ddagger$ & $1.147 \ddagger$ \\
\hline \multicolumn{7}{|l|}{$\begin{array}{l}\text { Marital status } \\
\quad \text { (Ref. married) }\end{array}$} \\
\hline Single & & $0.907 \ddagger$ & $0.907 \ddagger$ & $0.909 \ddagger$ & $0.907 \ddagger$ & 0.907 \\
\hline Divorced or separated & & 1.034 & 1.034 & 1.030 & 1.031 & $1.035 \S$ \\
\hline Widowed & & 0.982 & 0.983 & 0.984 & 0.982 & 0.999 \\
\hline \multicolumn{7}{|l|}{$\begin{array}{l}\text { Type of community } \\
\text { (Ref. Urban) }\end{array}$} \\
\hline Rural & & 0.981 & 0.981 & 0.981 & 0.981 & 0.980 \\
\hline Small urban & & $0.971 \S$ & $0.971 \S$ & $0.971 \S$ & $0.971 \S$ & $0.971 \S$ \\
\hline \multicolumn{7}{|l|}{ Education (Ref. high) } \\
\hline Low & & $0.730 \ddagger$ & $0.730 \ddagger$ & $0.730 \ddagger$ & $0.730 \ddagger$ & $0.780 \ddagger$ \\
\hline Middle & & $0.863 \ddagger$ & $0.864 \ddagger$ & $0.863 \ddagger$ & $0.863 \ddagger$ & $0.939 \S$ \\
\hline \multicolumn{7}{|l|}{ Interaction effect with sex } \\
\hline Female $\times$ low education & & & & & & $0,869 \|$ \\
\hline $\begin{array}{l}\text { Female } \times \text { middle } \\
\text { education }\end{array}$ & & & & & & $0.859 \ddagger$ \\
\hline $\begin{array}{l}\text { Cross-level interaction } \\
\text { effects with period }\end{array}$ & & & Sex & Age & Employment & Sex \\
\hline 1994 & & & 1.007 (female) & $0.952(18-29 y)$ & 0.921 (homemaker) & 1.037 (female) \\
\hline 2002 & & & 1.040 (female) & $1.003(18-29 y)$ & 0.971 (homemaker) & 1.032 (female) \\
\hline 2014 & & & 1.103 (female)‡ & $1.152(18-29 y) \ddagger$ & 1.034 (homemaker) & $\begin{array}{l}1.099 \text { (female) } \| \\
\text { Education }\end{array}$ \\
\hline 1994 & & & & $0.940(45-54 y)$ & 0.914 (student) & 1.049 (low) \\
\hline 2002 & & & & $1.067(45-54 \mathrm{y})$ & 0.889 (student)§ & 1.158 (low) $\|$ \\
\hline 2014 & & & & $1.024(45-54 \mathrm{y})$ & 1.101 (student) $\S$ & $\begin{array}{c}1.089 \text { (low) } \\
\text { Sex } \times \text { education }\end{array}$ \\
\hline 1994 & & & & 0.767 (55-64 y) & 0.911 (unemployed) & 0.834 (female/low)§ \\
\hline 2002 & & & & $0.978(55-64 \mathrm{y})$ & 1.009 (unemployed) & 0.821 (female/low) $\|$ \\
\hline 2014 & & & & $1.007(55-64 \mathrm{y})$ & 0.903 (unemployed)§ & 0.935 (female/low) \\
\hline 1994 & & & & & 0.796 (retired/disabled)‡ & \\
\hline 2002 & & & & & 0.966 (retired/disabled) & \\
\hline 2014 & & & & & 0.987 (retired/disabled) & \\
\hline $\begin{array}{l}\text { Variance: Country, } \\
\quad \sigma^{2} \pm \mathrm{SE}\end{array}$ & $0.116 \pm 0.038$ & $0.120 \pm 0.035$ & $0.122 \pm 0.036$ & $0.123 \pm 0.036$ & $0.123 \pm 0.036$ & $0.122 \pm 0.036$ \\
\hline $\begin{array}{l}\text { County } \times \text { period, } \\
\sigma^{2} \pm \mathrm{SE}\end{array}$ & $0.060 \pm 0.0135$ & $0.022 \pm 0.005$ & $0.021 \pm 0.005$ & $0.021 \pm 0.005$ & $0.021 \pm 0.005$ & $0.021 \pm 0.005$ \\
\hline VPC, $\sigma^{2}$ & 5.078 & 4.193 & 4.165 & 4.193 & 4.193 & 4.165 \\
\hline $\begin{array}{l}{ }^{*} \mathrm{~N} \text { country }=28, \mathrm{~N} \text { country } \\
\dagger \mathrm{In} \text { Model } 6, \text { the interacti } \\
\text { shown, because they we } \\
\ddagger \mathrm{p}<0.001 ; \mathrm{s}<0.050 ; \| \mathrm{p} \\
\text { Ref. = reference category; }\end{array}$ & $\begin{array}{l}y \text {-period }=82 \text {, and } \\
\text { on terms "period } \\
\text { re not significant. } \\
<0.010 \text {. } \\
\text { SE = standard er }\end{array}$ & $\begin{array}{l}\mathrm{d} \text { individual }= \\
\times \text { middle educ } \\
\text { rror; VPC, variar }\end{array}$ & $\begin{array}{l}62,237 . \\
\text { cation" and "perioc } \\
\text { nce partition coeff }\end{array}$ & $\begin{array}{l}\mathrm{d} \times \text { female } \times \text { mic } \\
\text { ficient. }\end{array}$ & iddle education" are also & included but are not \\
\hline
\end{tabular}


$\sigma^{2}$ period $] /\left[\sigma^{2}\right.$ country $+\sigma^{2}$ period +3.29$\left.]\right) ; 5.1 \%$ of individuals' blood donor status is influenced by the country and the period in which they are surveyed. Of the $5.1 \%$ variance $(\sigma), 3.3 \%$ is at the country level, and $1.7 \%$ is at the country-period level. When comparing the variance explained by country differences for each period individually $(5.2 \%$ in $1994,3.9 \%$ in $2002,4.9 \%$ in 2009 , and $2.6 \%$ in 2014), it seems possible that some convergence has occurred. The rise in variance between 2002 and 2009 might indicate diversity in the EU population after the first Eastern enlargement in 2004, when the Czech Republic, Estonia, Cyprus, Latvia, Lithuania, Hungary, Malta, Poland, Slovakia, and Slovenia joined the EU, and the second Eastern enlargement in 2007, with the joining of Bulgaria and Romania.

In line with the bivariate results, the first multilevel model, as presented in Table 2, shows that the likelihood of ever having donated blood is significantly higher in 2009 (reference category) than in 1994 (odds ratio $[\mathrm{OR}]=0.770), 2002(\mathrm{OR}=0.814)$, and $2014(\mathrm{OR}=0.939)$. However, the difference between 2009 and 2014 is not significant in the subsample of the age category 18 to 29 years (Appendix S2). After adding the sociodemographic variables to the model, only the period effects of 1994 $(\mathrm{OR}=0.813)$ and $2002(\mathrm{OR}=0.837)$ are slightly reduced, but they remain significant. This means that the period effects cannot be ascribed to a changed composition of the potential blood donor population.

All of the included sociodemographic and economic variables have a significant impact on the likelihood of ever having donated blood, which is lower among women $(\mathrm{OR}=0.750)$, those who live in small urban areas compared with large towns/cities $(\mathrm{OR}=0.971)$, and single individuals compared with married individuals $(\mathrm{OR}=0.907)$. A significant gender gap is found in almost every country (except Ireland, the United Kingdom, Malta, and Estonia) and is especially large in some Southern and Eastern European countries (Model 2, Appendix S4). Related to the nature of the outcome variable, age is positively related to ever having donated blood $\left(\mathrm{OR}_{\text {age }} 18-29\right.$, 0.802; $\mathrm{OR}_{\text {age }} 45-54,1.146$; and $\left.\mathrm{OR}_{\text {age } 55-65}, 1.145\right)$. In addition, the low $(\mathrm{OR}=0.730)$ and middle $(\mathrm{OR}=0.863)$ educated, as well as homemakers $(\mathrm{OR}=0.803)$, students $(\mathrm{OR}=0.813)$, the unemployed $(\mathrm{OR}=0.861)$, and retirees and the disabled $(\mathrm{OR}=0.944)$, are less likely to be blood donors compared with the higher educated and the employed, respectively. The country-specific results indicate that the educational gradient does not exist in some Northern European countries (the Netherlands, Finland, and Sweden) or in Cyprus. Furthermore, taking "EU inclusion" into account does not change the results.

We observe a gender gap in each period, but this gap is significantly smaller in 2014 (Table 2, Model 3) $\left(\mathrm{OR}_{\text {female }}\right.$ $\times 2014=1.103$ ). However, this finding is not confirmed in the youngest age group (Appendix S2). In addition, the age differences vary across the periods. In 1994, the difference between the group ages 30 to 44 years and the oldest group is significantly smaller than in 2009 (Table 2, Model 4) $\left(\mathrm{OR}_{\text {age category }} 55-65=0.767\right)$; whereas, in 2014 , the difference in the youngest age group is smaller (Table 2, Model

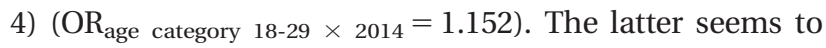
be an indication of a rejuvenation of the blood donor population or that the more recent birth cohort is more likely to donate blood (results with birth cohort are shown in Model 4, Appendix S3).

For employment status, the results from Model 5 (Table 2) show that there is a difference in blood donation between retirees or the disabled and the employed in $1994\left(\mathrm{OR}_{\text {retired/disabled } \times 1994}=0.796\right)$ but that this is no longer the case in $2009(\mathrm{OR}=0.982)$. Moreover, the lower likelihood of blood donor status for students is stronger in $2002\left(\mathrm{OR}_{\text {student }} \times 2002=0.889\right)$ and weaker in $2014\left(\mathrm{OR}_{\text {stu- }}\right.$ dent $\times 2014=1.101)$ compared with 2009. The difference in blood donor status between the employed and unemployed is stronger in $2014\left(\mathrm{OR}_{\text {unemployed }} \times 2014=0.902\right)$, and it persists among the younger subsample (Appendix S2).

Educational attainment seems to be related to blood donation more strongly among women $\left(\mathrm{OR}_{\text {female }} \times\right.$ low education $=0.869$; $\mathrm{OR}_{\text {female }} \times$ middle education $=0.859$ ). However, these educational inequalities appear be attenuated over time $\left(\mathrm{OR}_{\text {female }} \times\right.$ low education $\times 1994=0.834 ; \mathrm{OR}_{\text {female } \times \text { low }}$ education $\times 2002=0.821)$.

Finally, to assess sensitivity, these analyses were redone using the variable birth cohort instead of age. Because the results were similar, we only present results from the age variable (results from the birth cohort variable are shown in Appendix S3).

\section{DISCUSSION}

Demographic trends in Europe put pressure on the supply of donor-sourced blood. Working with data from four waves of the Eurobarometer, we performed a three-level and country-specific analysis, to answer the research question, "How do European countries' blood donor populations differ, and how have they evolved in the last 2 decades?"

Starting with our first question ("How do they differ?"), it is safe to say that, in general, they do not. The average proportion of people who have ever given blood over the four periods and all EU countries is $37.0 \%$. The donation rate increased from 1994 to 2009, with a small decrease in 2014. Although Central and Eastern European countries that entered the EU in enlargement rounds after the 1994 survey are characterized by more rapid demographic and sociopolitical changes from the early 1990s onward, ${ }^{7}$ no clear clustering of countries in terms of donor prevalence is observed. 
In general, our results confirm that the typical donor is a middle-aged, well-educated, married man. Both the gender gap and the educational gradient in blood donation are confirmed. However, and as a direct benefit of our cross-temporal design, we are able to observe important changes over time. Therefore, the answer to our second question ("How have they evolved in the last 2 decades?") is more layered. There are four ways in which the European donor populations have changed since 1994.

Although a gendered perspective on blood donation has been uncommon, ${ }^{43,44}$ women's donations are an important source of plasma for further processing into pharmaceuticals. ${ }^{45}$ The gender gap we observed in each of the four waves became smaller by 2014 compared with 2009 and the previous two periods. Thus, it is persistent, yet declining. First, a potential explanation for the persistence, despite the reduction, is women's deferral after presentation. ${ }^{4}$ Donor selection rules related to pregnancy, body height and weight, and hemoglobin levels for donor safety are likely to account for the under-representation of women in the group of actual donors. ${ }^{44,46}$ Any deferral, even temporary, has the collateral effect of reducing the likelihood of returning to donate in the future. ${ }^{9,44}$ Second, the gap's persistence was to be expected, because selection rules have not changed, and sudden changes in European women's body weight, height, or fertility between 2009 and 2014 are unlikely. Furthermore, because the classic deterrents for women noted in previous reviews remain plausible, ${ }^{46}$ the gender gap's decline remains puzzling. Nevertheless, it is consistent with recent research from the Netherlands and Spain, which found that more new donors were female and somewhat younger. ${ }^{3,18} \mathrm{~A}$ potential explanation is that the gap is closing because of gender differences in motivation. Because women more often report motivation for altruistic reasons, ${ }^{29,46}$ and recruitment strategies in Europe-which have been professionalized over recent decades-emphasize voluntary, non-remunerated blood donation, ${ }^{1}$ these strategies might be disproportionately successful in motivating women. ${ }^{27,46}$ The declining gender gap also may be related to the changing patterns we observed in the relationship between education and blood donation.

For differences in donor prevalence due to educational attainment, we find a stronger gap for women, which is contrary to earlier findings. ${ }^{30}$ Between 2009 and 2014, however, the influence of education on blood donation was similar for men and women. It is possible that women's increasing participation in higher education ${ }^{47}$ has contributed to the decline of the overall gender gap in blood donation in indirect and direct ways. Education may influence blood donation behavior indirectly because of its beneficial effects on health outcomes, ${ }^{48}$ mediating the health-selection effects of blood donors. However, education may also influence donation behavior directly by providing knowledge of blood donation necessity and procedures. Furthermore, a combination of the disappearance of the wider educational gap among women and the persistence of the general gender gap may indicate diminishing marginal returns from higher education with regard to blood donation throughout the periods assessed, which would be consistent with diminishing health returns from education. ${ }^{48}$ Although the educational disparity in blood donation was previously attributed to an inclination of the lower educated toward free-riding behavior, ${ }^{12}$ we believe a more likely explanation is differential awareness of the necessity of blood donation. Because awareness has been identified as an important donation motivator, ${ }^{37}$ it is possible that people with lower educational levels are less aware of the need and thus donate less. This discrepancy could be mediated by informing students about the procedures and the necessity for blood donation during the compulsory stages of education.

With regard to donation patterns in age groups, we observe that, compared with 2009, the difference in donor prevalence became smaller in 2014 among the middleaged group (30-44 years) and the youngest age group. This seems to be a hopeful indicator, because it might mean that a rejuvenation of the donor base is taking place.

Apart from these changes over time in the more commonly studied demographic determinants, we aimed to elaborate on current knowledge about the donor population through our addition of employment status and type of community. We find that donors are typically employed, which is probably related to the organization of on-site blood drives at the workplace as a recommended practice. ${ }^{5,38,49}$ However, some change over time can also be observed here. Throughout the periods assessed, students seem to be reached better by establishments. A final change over time is rather worrying. It appears that the gap between the unemployed and employed was wider by 2014 , with the unemployed donating less than they did in 2009. Moreover, this trend persisted when observing only the younger subsample. It might be beneficial to work with public centers for social welfare or employment and vocational training services in order to reach out to the unemployed. Although we are aware that this can be deemed close to the classic "slippery slope" argument in the ethics of blood donation behavior, ${ }^{50,51}$ it has also been demonstrated that donation contributes to people's sense of citizenship and belonging. ${ }^{21,52}$ In addition, with regard to the type of community, our results are less straightforward. However, we find that blood donors generally are more likely to live in a large city compared with a small urban area and that these differences are more pronounced in Scandinavian countries. Further development of mobile blood-collection centers, which have already been organized to target underreached areas, ${ }^{53}$ is recommended. 
There are some limitations to our study related to the Eurobarometer data. First, measuring donor prevalence instead of incidence warrants careful interpretation. Prevalence, as a cumulative measurement, is logically greater for older people, who have had more time and opportunities to have ever given blood throughout their life course. We mediated this problem by re-estimating our models on the youngest age category (Appendix S2). In addition, because of the overlap with birth cohort, it is difficult to unravel the two effects, which hinders making strong conclusions about the age and birth cohort of the typical donor. Second, reliance on self-reported donor status can cause biased responses related to social desirability. ${ }^{30,37}$ However, given the lack of alternatives, no other variable would allow us to study blood donation patterns in such a wide range of countries and over time. Third, although migration has been recognized as an important demographic shift for the collection of blood in Europe, ${ }^{8,54-56}$ the Eurobarometer lacks systematic data to take this into account. Only $2 \%$ of respondents in our sample indicated they were born in a country different from their country of residence, and the reported status only allows the inclusion of first-generation immigrants. Finally, the response rates for the waves we used were not available. We are left with just one tool to address the representativeness of the Eurobarometer surveys: post-stratification weights, which we have used.

Notwithstanding these limitations, our study has important strengths. To the best of our knowledge, it is the first to examine blood donation across a wide range of European countries over time using a multilevel framework. Previous cross-national, cross-temporal research studied only two countries and two points in time. ${ }^{30}$ Furthermore, our study also takes into account marital status, type of community, and employment status to enhance our understanding of donor populations.

To help face the major challenge of donor recruitment because of ageing populations, this study provides answers to the question, "who donates," by considering the evolution of donor populations since 1994 and by highlighting which subpopulations still need more attention to be reached. Although our results show a promising trend, in which women, young people, and students are increasingly likely to donate, more attention is needed to reach the unemployed and the low and medium educated. Given our proposed explanation, that the unemployed may lack structural opportunities to donate, and that the low and medium educated may lack important knowledge about blood donation necessity and practices, we recommend that establishments reach out to both demographics, providing knowledge and practical opportunities.

\section{CONFLICT OF INTEREST}

The authors have no conflicts of interest to declare.

\section{REFERENCES}

1. European Blood Alliance. Blood, tissues, and cells from human origin: the European Blood Alliance perspective. Amsterdam (the Netherlands): European Blood Alliance; 2013.

2. Ali A, Auvinen MK, Rautonen J. Blood donors and blood collection: the aging population poses a global challenge for blood services. Transfusion 2010;50:584-8.

3. Borkent-Raven BA, Janssen MP, Van Der Poel CL. Demographic changes and predicting blood supply and demand in the Netherlands. Transfusion 2010;50:2455-60.

4. Greinacher A, Fendrich K, Brzenska R, et al. Implications of demographics on future blood supply: a population-based cross-sectional study. Transfusion 2011;51:702-9.

5. De Kort W, Veldhuizen I, editors; Donor Management in Europe (DOMAINE) Project Partners. Donor management manual 2010 [cited 2017 Aug 17]. Nijmegen, the Netherlands: DOMAINE Project; 2010. Available at: https://www. sanquin.nl/en/research/departments/donor-studies/ domaine/.

6. Healy K. Embedded altruism: blood collection regimes and the European Union's donor population. Am J Sociol 2000; 105:1633-57.

7. Botev N. Population ageing in Central and Eastern Europe and its demographic and social context. Eur J Ageing 2012;9: 69-79.

8. Cimaroli K, Páez A, Newbold KB, et al. Individual and contextual determinants of blood donation frequency with a focus on clinic accessibility: a case study of Toronto, Canada. Health Place 2012;18:424-33.

9. Hillgrove TL, Doherty KV, Moore VM. Understanding nonreturn after a temporary deferral from giving blood: a qualitative study. BMC Public Health 2012;12:1.

10. Lacetera N, Macis M, Slonim R. Economic rewards to motivate blood donations. Science 2013;340:927-8.

11. Lacetera N, Macis M. Social image concerns and prosocial behavior: field evidence from a nonlinear incentive scheme. J Econ Behav Org 2010;76:225-37.

12. Abásolo I, Tsuchiya A. Egalitarianism and altruism in health: some evidence of their relationship. Int J Equity Health 2014; 13:13.

13. Chou EY, Murnighan JK. Life or death decisions: framing the call for help. PLoS One 2013;8:e57351.

14. Pruvot J, Calafiore M, Dambricourt PA, et al. Non-donor patients' opinions about general practitioners' influence on first blood donation [Article in French]. Rev Epidemiol Sante Publique 2015;63:326-31.

15. Charles-Sire V, Guéguen N, Pascual A, et al. Words as environmental cues: the effect of the word "loving" on compliance to a blood donation request. J Psychol 2012;146:455-70.

16. Lemmens KP, Ruiter RA, Abraham C, et al. Motivating blood donors to recruit new donors: experimental evaluation of an evidence-based behavior change intervention. Health Psychol 2010;29:601-9. 
17. van Dongen A, Abraham C, Ruiter RA, et al. Does questionnaire distribution promote blood donation? An investigation of question-behavior effects. Ann Behav Med 2013;45:16372.

18. Lemmens K, Abraham C, Ruiter R, et al. Modelling antecedents of blood donation motivation among non-donors of varying age and education. Br J Psychol 2009;100:71-90.

19. Godin G, Sheeran P, Conner M, et al. Which survey questions change behavior? Randomized controlled trial of mere measurement interventions. Health Psychol 2010;29:636-44.

20. Leipnitz S. Stakeholder performance measurement in nonprofit organizations. Nonprofit Manag Leadersh 2014;25:165-81.

21. Duboz P, Boëtsch G, Cunéo B. Le don de sang des populations étrangères et d'origine étrangère à Marseille. Santé Publique 2010;22:379-91.

22. Ritter S, Willand L, Reinhard B, et al. Blutspenderpopulationen in Deutschland: demographie und spendeaktivität. Bundesgesundheitsblatt Gesundheitsforschung Gesundheitsschutz 2008;51:915-25.

23. Ritter S, Hamouda O, Offergeld R. Demografie und spendeaktivität von blut-und plasmaspendern in Deutschland. Bundesgesundheitsblatt Gesundheitsforschung Gesundheitsschutz 2012;55:914-22.

24. Shehu E, Hofmann A, Clement M, et al. Healthy donor effect and satisfaction with health. Eur J Health Econ 2015;16:73345.

25. Hâţu G, Brumboiu M, Gorgan I, et al. Romanian blood donors screening: is it really necessary and/or mandatory? Rev Med Chir Soc Med Nat Iasi 2012;117:741-6.

26. Shehu E, Langmaack AC, Felchle E, et al. Profiling donors of blood, money, and time. Nonprofit Manag Leadersh 2015;25: 269-95.

27. Lacetera N, Macis M. Do all material incentives for pro-social activities backfire? The response to cash and non-cash incentives for blood donations. J Econ Psychol 2010;31:738-48.

28. Lacetera N, Macis M. Time for blood: the effect of paid leave legislation on altruistic behavior. J Law Econ Org 2013;29: 1384-420.

29. Bani M, Strepparava MG. Motivation in Italian whole blood donors and the role of commitment. Psychol Health Med 2011;16:641-9.

30. Volken T, Weidmann C, Bart T, et al. Individual characteristics associated with blood donation: a cross-national comparison of the German and Swiss population between 1994 and 2010. Transfus Med Hemother 2013;40:133-8.

31. Muszyńska MM, Rau R. The old-age healthy dependency ratio in Europe. J Popul Ageing 2012;5:151-62.

32. Berigan N, Irwin K. Culture, cooperation, and the general welfare. Soc Psychol Q 2011;74:341-60.

33. Bracke P, Van De Straat V, Missinne S. Education, mental health, and education-labor market misfit. J Health Soc Behav 2014;55:442-59.

34. Bracke P, Pattyn E, dem Knesebeck O. Overeducation and depressive symptoms: diminishing mental health returns to education. Sociol Health Illn 2013;35:1242-59.
35. Ameratunga SN, Norton RN, Whitlock G, et al. The New Zealand Blood Donors' Health Study: baseline findings of a large prospective cohort study of injury. Inj Prev 2002;8:66-9.

36. Simon TL. Where have all the donors gone? A personal reflection on the crisis in America's volunteer blood program. Transfusion 2003;43:273-9.

37. Bednall TC, Bove LL. Donating blood: a meta-analytic review of self-reported motivators and deterrents. Transfus Med Rev 2011;25:317-34.

38. Boulware L, Ratner L, Ness P, et al. The contribution of sociodemographic, medical, and attitudinal factors to blood donation among the general public. Transfusion 2002;42:669-78.

39. Harrington M, Sweeney MR, Bailie K, et al. What would encourage blood donation in Ireland? Vox Sang 2007;92:361-7.

40. Zimrin AB, Hess JR. Blood donors and the challenges in supplying blood products and factor concentrates. Surgery 2007; 142:S15-9.

41. Fairbrother M. Two multilevel modeling techniques for analyzing comparative longitudinal survey datasets. Political Sci Res Methods 2014;2:119-40.

42. Mood C. Logistic regression: why we cannot do what we think we can do, and what we can do about it. Eur Sociol Rev 2010;26:67-82.

43. Kent J, Farrell AM. Risky bodies in the plasma bioeconomy: a feminist analysis. Body Soc 2014;21:29-57.

44. Madrona DP, Herrera MDF, Jimenez DP, et al. Women as whole blood donors: offers, donations and deferrals in the province of Huelva, south-western Spain. Blood Transfus 2014;12:S11-20.

45. Sheikh Z, Deleuran I, Hoeyer K. Silenced uses and moral ideals in the exchange of Danish blood and plasma. BioSocieties 2016;11:106-22.

46. Bani M, Giussani B. Gender differences in giving blood: a review of the literature. Blood Transfus 2010;8:278-87.

47. Ranguelov S, De Coster I, Norani S, et al. Key data on education in Europe 2012. Brussels (Belgium): Education, Audiovisual and Culture Executive Exchange Agency; 2012.

48. Mirowsky J, Ross CE. Education, social status, and health. Piscataway (NJ): Transaction Publishers; 2003.

49. McVittie C, Harris L, Tiliopoulos N. "I intend to donate but. ..": non-donors' views of blood donation in the UK. Psychol Health Med 2006;11:1-6.

50. Farrell AM. The politics of risk and EU governance of human material. Maastrich J Eur Comp Law 2009;16:41-64.

51. Titmuss RM. The gift relationship. London (UK): George Allen and Unwin; 1970. Vol. 19, p. 70.

52. Valentine K. Citizenship, identity, blood donation. Body Soc 2005;11:113-28.

53. European Union Commission. Overview of the landscape of blood and plasma derivatives focusing on their availability for patients. Creative Ceutical report, revised by the commission to include stakeholders' comments. Brussels (Belgium): European Union Commission; 2015.

54. Polonsky MJ, Renzaho A, Brijnath B. Barriers to blood donation in African communities in Australia: the role of home and host country culture and experience. Transfusion 2011;51:1809-19. 
55. Boenigk S, Mews M, de Kort W. Missing minorities: explaining low migrant blood donation participation and developing recruitment tactics. VOLUNTAS 2015;26: 1240-60.

56. van Dongen A, Mews M, de Kort W, et al. Missing minorities? A survey based description of the current state of minority blood donor recruitment across 23 countries. Divers Equal Health Care 2016;13:138-45.

\section{SUPPORTING INFORMATION}

Additional Supporting Information may be found in the online version of this article at the publisher's website.

Appendix S1. Descriptive results, sample size, and the prevalence of ever having given blood per country and period
Appendix S2. Results of the three-level logistic regression analysis on ever having given blood $(\mathrm{N}$ country=28; $\mathrm{N} \quad$ country-period $=82 ; \mathrm{N}$ individu$\mathrm{al}=13,588)$; subsample of 18 to 29 year olds

Appendix S3. Results of the three-level logistic regression analysis on ever having given blood with birth cohort instead of age groups

Appendix S4.1. Country-specific logistic regression analyses on blood donation (part 1)

Appendix S4.2. Country-specific logistic regression analyses on blood donation (part 2)

Appendix S4.3. Country-specific logistic regression analyses on blood donation (part 3)

Appendix S4.4. Country-specific logistic regression analyses on blood donation (part 4)

Appendix S4.5. Country-specific logistic regression analyses on blood donation (part 5) 